\title{
TEOREMAS-EM-AÇÃO E CONCEITOS-EM-AÇÃO NA FÍSICA APLICADA À MEDICINA $^{1}$
}

\section{THEOREMS-IN-ACTION AND CONCEPTS- IN-ACTION IN APPLIED PHYSICS IN MEDICINE}

\author{
Mara Fernanda Parisoto1, Marco Antonio Moreira ${ }^{2}$ e José Tullio Moro ${ }^{3}$ \\ 1Doutoranda em Ensino de Física pela Universidade Federal do Rio Grande do Sul, marafisica@ hotmail.com \\ 2 Professor e pesquisador em Ensino de Física pela Universidade Federal do Rio Grande do Sul, \\ moreira@if.ufrgs.br \\ ${ }^{3}$ Professor Universidade Feevale, tullio.moro@ufrgs.br
}

\section{RESUMO}

Buscamos analisar três situações-problema que fazem parte de um curso que trata da Física aplicada à Medicina para dar sentido aos conceitos do campo conceitual relativo a Óptica, Eletromagnetismo e Física Moderna. Os nossos objetivos foram: 1) encontrar possíveis teoremas-em-ação e conceitosem-ação; 2) buscar indícios de aprendizagem significativa; 3) desenvolver uma ficha para cada aluno colocando os pontos que eles apresentam erros ou falta de conhecimento, utilizando tal ficha em uma entrevista semiestruturada. Utilizamos, para tanto, a Teoria dos Campos Conceituais de Vergnaud e a Teoria da Aprendizagem Significativa de Ausubel. Concluímos que na maioria dos casos os alunos nos forneceram indícios de aprendizagem significativa e, portanto, que o material elaborado e implementado é potencialmente significativo.

Palavras-chave: ensino de Física, teoremas-em-ação, conceitos-em-ação, Física aplicada à Medicina, aprendizagem significativa.

\begin{abstract}
We analyze three problem situations that are part of a course that used Physics applied to Medicine to give meaning to the concepts relative to Optics, Electromagnetism and Modern Physics. Our objectives were: 1) to find possible theorems-in-action and concepts-in-action; 2) seek evidence of meaningful learning; 3) develop a form for each student, putting the points they were wrong or where there were lack of knowledge, using this plug in a semistructured interview. We used Vergnaud's Conceptual Fields Theory and Ausubel's Meaningful Learning Theory. We conclude that in most cases there were evidences of meaningful learning, so the applied material is potentially meaningful.
\end{abstract}

Keywords: teaching physics, theorems-in-action, concepts-in-action, Physics applied to Medicine, meaningful learning.

\footnotetext{
${ }^{1}$ Apoio: Coordenação de Aperfeiçoamento de Pessoal de Nível Superior (CAPES).
} 


\section{Introdução}

Investigando as aplicações do Eletromagnetismo, da Óptica e da Física Moderna na Medicina foi possível desenvolver uma proposta alternativa, que originou um curso, para ensinar conceitos de Física aplicados na Medicina. Não será posta no presente artigo a descrição detalhada do curso, que encontra-se em PARISOTO, 2011.

Tal curso utilizou várias estratégias de ensino de modo a buscar atingir os alunos que aprendem de modos distintos: visual, auditivo e cinestésico (PRAIN e WALDRIP, 2006). Tais estratégias foram: organizadores prévios, que são materiais que fazem uma ponte entre o que o aluno sabe e o que será ensinado (AUSUBEL, 2002); discussão, pelos alunos, de situaçõesproblema (VERGNAUD, 1993); filmes; modelagem e simulações computacionais (DORNELES, ARAÚJO e VEIT, 2006); diagrama V de Gowin (NOVAK e GOWIN, 1984); confecção de mapas conceituais (MOREIRA, 1980 e 2010); apresentações; aulas expositivas dialogadas; entrevistas semiestruturadas (ANDRÉ, 1998 e 2005); debates; atividades experimentais; colagens e resolução de exercícios.

No desenvolvimento do curso buscamos partir do que os alunos sabem, ou seja, de seus conhecimentos prévios. Para saber quais eram tais conhecimentos, foi aplicado um pré-teste. O curso foi dividido em quatro encontros, começando sempre com um organizador prévio, que possuía por objetivo fazer uma ponte do que o aluno sabia com o que iria ser ensinado. Posteriormente, era lançada uma situação-problema para que os alunos buscassem resolvê-la. Posteriormente, foi ministrada a aula sobre os conceitos que envolviam a situação-problema, intercalando as aulas expositivas-dialogadas com as estratégias mencionadas no parágrafo anterior. No final da aula foi solicitado aos alunos que buscassem novamente resolver a situação-problema.

A relevância didática e acadêmica deste trabalho está no fato dele mostrar um possível método para o professor analisar constantemente o aprendizado dos alunos e sua própria prática. Sendo necessário, retomar os conteúdos sempre que houver necessidade, pois os conhecimentos demoram um determinado tempo para serem aprendidos significativamente. Este trabalho também divulga uma forma dos professores de Física ensinarem conceitos de Física Médica de modo integrado, apresentando situações-problema para tanto. Além disso, foram identificados invariantes operatórios nessa área, que é pouco explorada, que pode vir a facilitar futuras pesquisas neste campo de atuação e favorecer um ensino que considere os conhecimentos-em-ação e os teoremasem-ação por nós identificados. 


\section{Fundamentação teórica}

Embasamo-nos teoricamente na Teoria dos Campos Conceituais de VERGNAUD (1993) e na Teoria de Aprendizagem Significativa (TAS) de AUSUBEL (2002).

Vergnaud define campo conceitual como um conjunto de problemas e situações cujo tratamento requer representações, conceitos e procedimentos de tipos diferentes, mas intimamente relacionados.

Os campos conceituais são dominados progressivamente pelo sujeito através de invariantes operatórios, sobre os quais repousa a operacionalidade dos conceitos e que formam o significado dos mesmos. Os invariantes operatórios são divididos em teoremas-em-ação e conceitos-em-ação.

Um conceito-em-ação não é inteiramente um conceito, nem um teorema-em-ação é um teorema. Na ciência os conceitos e teoremas são explícitos e se pode discutir sua permanência e validade. Isto não ocorre necessariamente para os invariantes operatórios. Geralmente, estes são implícitos e pode ser difícil explicitá-los. Um conceito-em-ação é um conhecimento necessário para resolver um problema ou uma questão. Através dele identificamos informações necessárias para resolver problemas, mas ele não permitem operar. Para isso usamos os teoremas-em-ação que são formados pelos conceitos-em-ação. Ambos não podem ser considerados verdadeiros, mas relevantes ou irrelevantes. Apenas os teoremas científicos podem ser considerados verdadeiros ou falsos.

Também foi utilizada a Teoria de Aprendizagem Significativa (TAS) de Ausubel (2002). Segundo a TAS o fator que mais influencia na aprendizagem significativa são os conhecimentos prévios que o sujeito possui em sua estrutura cognitiva.

Dessa forma, foi solicitado aos alunos que respondessem várias situações-problema para buscarmos indícios $^{2}$ de aprendizagem significativa e de conhecimentos prévios. Para ensinar foi utilizado o conhecimento prévio dos alunos; por este motivo, foi incentivado que estes, antes da aplicação do curso, buscassem resolver as situações-problema. No entanto, como eles, geralmente, não sabiam o que significavam muitos conceitos e se sabiam não conseguiam relacioná-los de modo a conseguir resolver as situações-problema, dificilmente chegavam a resolvê-las antes da aplicação do curso.

\footnotetext{
${ }^{2}$ o termo indícios de Aprendizagem Significativa, ou evidências de Aprendizagem Significativa, está sendo usado de um ponto de vista pessoal, subjetivo, interpretativo, ou seja, aquilo que os pesquisadores julgam ser indicadores dessa aprendizagem, em uma perspectiva de progressividade.
} 


\section{Metodologia das aulas}

$\mathrm{Na}$ metodologia das aulas foram utilizadas (em ordem cronológica) as seguintes etapas: $1^{\circ}$ ) no início da aula em duplas, os alunos gravaram, no programa Audacity, as discussões deles relativas a uma situação-problema; $2^{\circ}$ ) aplicação de uma parte do curso; $3^{\circ}$ ) no final da aula, em duplas, os alunos gravaram, no programa Audacity, a discussão deles relativo à mesma situaçãoproblema do começo da aula; $4^{\circ}$ ) discussão com os alunos sobre os equívocos apresentados, enfrentando, desta forma, os erros conceituais, buscando levar os conceitos e teoremas de senso comum para os científicos e os conceitos e teoremas implícitos encontrados (conceitos-em-ação e teoremas-em-ação) para conceitos e teoremas explícitos; $5^{\circ}$ ) os pontos que não foram mencionados ou que apresentavam equívocos na gravação das situações-problema foram retomados com os alunos.

\section{Metodologia da análise}

Para fazermos a análise utilizamos os seguintes passos: $1^{\circ}$ ) transcrição das respostas gravadas pelos alunos; $2^{\circ}$ ) análise destas transcrições buscando: a) equívocos apresentados; b) teoremas-em-ação; c) conceitos-em-ação; d) indícios de aprendizagem significativa; e) pontos que os alunos não explicaram.

\section{Descrição do grupo de trabalho}

O curso foi realizado em 4 sábados, com carga horária semanal de oito horas, totalizando 32 horas de curso presenciais e mais oito de atividades à distância.

O grupo era formado por seis participantes, sendo quatro da licenciatura em Física, um professor de Física do Instituto Federal do Rio Grande do Sul (IFRGS) e uma professora de Ensino Médio do mesmo estado.

\section{Análises das situações-problema}

Analisaremos agora as respostas dadas a três situações-problema pelos alunos com três objetivos: 1) encontrar possíveis teoremas-em-ação e conceitos-em-ação; 2) buscar indícios de aprendizagem significativa; 3) fazer uma ficha para cada aluno, colocando os pontos que eles apresentam erros ou falta de conhecimento. Tal ficha foi utilizada em uma entrevista semiestruturada, que foi aplicada ao final do curso, com o objetivo de identificar os tópicos que eles ainda apresentam dúvidas ou não deixaram claro em suas respostas, fornecendo um feedback a eles, ressaltando, desta forma o erro. 
Para isso fizemos, inicialmente, uma tabela. Esta contém na primeira coluna o nome fictício dos alunos, na segunda a transcrição de suas respostas, na terceira os equívocos apresentados, na quarta e quinta coluna, respectivamente os possíveis conceitos-em-ação e teoremas-em-ação. Desta forma, alcançamos nosso primeiro objetivo. Os equívocos apresentados nas Tabelas 1, 2 e 3 geraram uma ficha para cada aluno (tais fichas não serão aqui apresentadas devido às limitações de espaço) que era o terceiro objetivo. Por último, para buscar indícios de aprendizagem significativa (segundo objetivo) analisaremos as respostas dadas pelos alunos.

$\mathrm{Na}$

o efeito fotoelétrico é o maior responsável pela absorção da radiação e é proporcional a $Z^{3}$.

Com base nas afirmações acima, explique para um paciente, por que usamos placa de chumbo para se proteger dos Raios-X?"

Os alunos não conseguiram responder antes da aula, esta situação-problema, provavelmente, por não conseguirem relacionar o número atômico e o efeito fotoelétrico com o uso do chumbo para nos protegermos dos Raios-X. O único aluno que arriscou um palpite foi o aluno Marcelo (nome fictício), relacionando, corretamente, o bloqueio dos Raios-X, pelo chumbo, à sua densidade. Embora a resposta tenha um argumento correto é bastante superficial, no sentido que não relaciona a densidade, o número atômico, o efeito fotoelétrico e a absorção de Raios-X pelo chumbo.

Os alunos do grupo 1 foram os que mostraram mais equívocos após a aplicação da aula, conforme pode-se ver na Erro! Autoreferência de indicador não válida.. Entretanto, conseguiram relacionar corretamente o número atômico, o número de elétrons, o efeito fotoelétrico e o porquê da utilização do chumbo e não de outro material com menor número atômico para se proteger dos Raios-X. Não explicaram por que não são utilizados materiais com números atômicos mais elevados do que o chumbo. Devido aos diversos equívocos encontrados nas explicações dos alunos, não podemos dizer que houve indícios de aprendizagem significativa.

Os alunos do grupo 2 apresentaram apenas um equivoco, conforme pode-se ver na Tabela 1 e não explicaram o que são e o que torna um átomo estável (em termos das forças que agem nele). O restante apresenta-se explicado de forma clara e correta, o que nos sugeriu indícios de aprendizagem significativa, nestes pontos.

Os alunos do grupo 3 não relacionaram a quantidade de elétrons ao número atômico, mas mencionaram corretamente a necessidade de haver mais elétrons com o efeito fotoelétrico, o que 
nos apresentou indícios de aprendizagem significativa neste ponto. Mas, não explicaram por que utiliza-se chumbo e não outros tipos de materiais. Neste tópico o grupo não nos forneceu indícios de aprendizagem, nem mecânica nem significativa.

Na tabela 2 temos a análise da segunda situação-problema que é: "imagine que você é um técnico em radiologia, você precisa distinguir dois tecidos internos que possuem densidades semelhantes, como você faria? Pense a sua resposta em termos de contraste".

$\mathrm{Na}$ segunda situação-problema os alunos tiveram argumentos para responder antes e após a aula. 
Tabela 1 temos a análise da primeira situação-problema que é: "suponha que você seja técnico em radiologia e soubesse que:

- o chumbo possui um número atômico (Z) elevado (82);

- o efeito fotoelétrico é o maior responsável pela absorção da radiação e é proporcional a $Z^{3}$.

Com base nas afirmações acima, explique para um paciente, por que usamos placa de chumbo para se proteger dos Raios-X?"

Os alunos não conseguiram responder antes da aula, esta situação-problema, provavelmente, por não conseguirem relacionar o número atômico e o efeito fotoelétrico com o uso do chumbo para nos protegermos dos Raios-X. O único aluno que arriscou um palpite foi o aluno Marcelo (nome fictício), relacionando, corretamente, o bloqueio dos Raios-X, pelo chumbo, à sua densidade. Embora a resposta tenha um argumento correto é bastante superficial, no sentido que não relaciona a densidade, o número atômico, o efeito fotoelétrico e a absorção de Raios-X pelo chumbo.

Os alunos do grupo 1 foram os que mostraram mais equívocos após a aplicação da aula, conforme pode-se ver na Erro! Autoreferência de indicador não válida.. Entretanto, conseguiram relacionar corretamente o número atômico, o número de elétrons, o efeito fotoelétrico e o porquê da utilização do chumbo e não de outro material com menor número atômico para se proteger dos Raios-X. Não explicaram por que não são utilizados materiais com números atômicos mais elevados do que o chumbo. Devido aos diversos equívocos encontrados nas explicações dos alunos, não podemos dizer que houve indícios de aprendizagem significativa.

Os alunos do grupo 2 apresentaram apenas um equivoco, conforme pode-se ver na Erro! Autoreferência de indicador não válida. e não explicaram o que são e o que torna um átomo estável (em termos das forças que agem nele). O restante apresenta-se explicado de forma clara e correta, o que nos sugeriu indícios de aprendizagem significativa, nestes pontos.

Os alunos do grupo 3 não relacionaram a quantidade de elétrons ao número atômico, mas mencionaram corretamente a necessidade de haver mais elétrons com o efeito fotoelétrico, o que nos apresentou indícios de aprendizagem significativa neste ponto. Mas, não explicaram por que utiliza-se chumbo e não outros tipos de materiais. Neste tópico o grupo não nos forneceu indícios de aprendizagem, nem mecânica nem significativa. 
Ensino, Saúde e Ambiente - V6 (3), pp. 114-128, dez. 2013

Na Tabela 2 temos a análise da segunda situação-problema que é: "imagine que você é um técnico em radiologia, você precisa distinguir dois tecidos internos que possuem densidades semelhantes, como você faria? Pense a sua resposta em termos de contraste".

Na segunda situação-problema os alunos tiveram argumentos para responder antes e após a aula. 
Tabela 1 - Análise das respostas à primeira situação-problema.

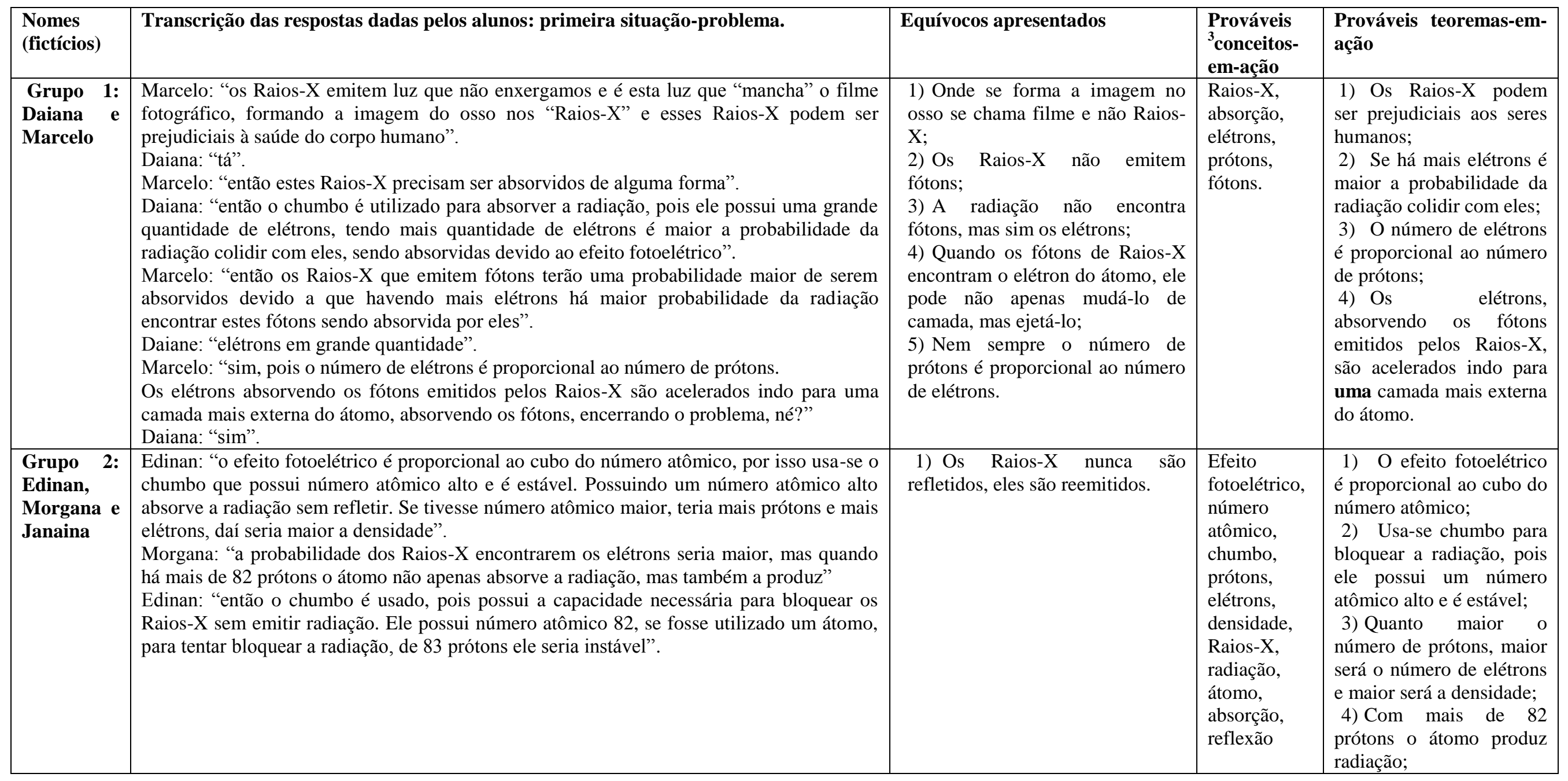

${ }^{3}$ São possíveis, pois para aumentar a confiabilidade são necessários mais testes. 


\begin{tabular}{|c|c|c|c|c|}
\hline $\begin{array}{lr}\text { Grupo } & 3: \\
\text { Marta } & \text { e } \\
\text { Maria } & \end{array}$ & $\begin{array}{l}\text { Maria: "o chumbo tem muita densidade e possui bastante elétrons, daí os Raios-X vão } \\
\text { penetrar e vão ser absorvidos por estes elétrons e daí vai transformar em energia cinética do } \\
\text { elétron e não num comprimento de onda". } \\
\text { Marta: "ou seja, vai ser completamente absorvido não deixando passar a radiação para a } \\
\text { pessoa. Mais alguma coisa?". } \\
\text { Maria: "não, é isto mesmo, pois é a relação de não deixar passar a radiação para a pessoa } \\
\text { em função dela ser massiva". }\end{array}$ & $\begin{array}{l}\text { Não há equívocos, entretanto não } \\
\text { explicaram por que usa-se } \\
\text { chumbo e não outro elemento com } \\
\text { maior número atômico. }\end{array}$ & $\begin{array}{l}\text { Elétrons, } \\
\text { chumbo, } \\
\text { Raios-X, } \\
\text { onda, } \\
\text { energia } \\
\text { cinética, } \\
\text { absorção, } \\
\text { radiação. }\end{array}$ & $\begin{array}{l}\text { 1) Devido à densidade e } \\
\text { a quantidade de elétrons do } \\
\text { chumbo, os Raios-X são } \\
\text { bloqueados; } \\
\text { 2) Os fótons dos Raios-X } \\
\text { são transformados em } \\
\text { energia cinética do elétron. }\end{array}$ \\
\hline
\end{tabular}

Os alunos tanto do grupo 1 quanto do grupo 2 não apresentaram, em suas respostas posteriores a aula, nenhum equivoco, mudando a situação, antes da aplicação, em que o grupo 1 apresentou dois equívocos, portanto, forneceram indícios de Aprendizagem Significativa.

Os dois grupos não explicaram por que se há dois materiais com contrastes diferentes teremos imagens diferentes, embora, isto não tenha sido perguntado explicitamente na situação-problema. Foi perguntado tais pontos na entrevista semiestruturada e nas próximas implementações foi colocado isto na situação-problema.

Ambos os grupos deram maior ênfase à explicação do que à descrição o que, segundo AUSUBEL (2002), são indícios de aprendizagem significativa.

Tabela 2 - Análise das respostas à segunda situação-problema.

\begin{tabular}{|c|c|c|c|c|}
\hline $\begin{array}{l}\text { Nomes } \\
\text { (fictícios) }\end{array}$ & Transcrição do respondido pelos alunos: segunda situação-problema. & Equívocos apresentados & $\begin{array}{l}\text { Prováveis } \\
\text { conceitos- } \\
\text { em-ação }\end{array}$ & $\begin{array}{l}\text { Prováveis teoremas-em- } \\
\text { ação }\end{array}$ \\
\hline $\begin{array}{l}\text { Grupo1: } \\
\text { Morgana } \\
\text { e Janaina }\end{array}$ & $\begin{array}{l}\text { Antes da aula. } \\
\text { Janaína: "o contraste será maior no tecido menos denso, então o que for mais } \\
\text { escurinho será mais denso e o outro será menos denso, o que for mais claro". } \\
\text { Morgana: "mas como dá para distinguir eles?" } \\
\text { Janaína: "pela imagem, vai dar para ver na imagem." } \\
\text { Morgana: "ah, é essa a resposta será?" } \\
\text { Janaína: "tomara que sim". } \\
\text { Morgana: "tu vai fazer a imagem igual e analisar depois"... }\end{array}$ & $\begin{array}{l}\text { Antes da aula: } \\
\text { 1) o contraste deve ser } \\
\text { medido em função de } \\
\text { algo. Não posso dizer que } \\
\text { tal tecido possui mais ou } \\
\text { menos contraste; } \\
\text { 2) a imagem, para ser } \\
\text { mais clara ou mais }\end{array}$ & $\begin{array}{l}\text { Antes da } \\
\text { aula: } \\
\text { contraste, } \\
\text { densidade, } \\
\text { imagem. } \\
\text { Depois da } \\
\text { aula: } \\
\text { contraste, }\end{array}$ & $\begin{array}{l}\text { Antes da aula: } \\
\text { 1) o contraste é } \\
\text { relacionado com a } \\
\text { densidade do material; } \\
\text { 2) contraste é maior no } \\
\text { tecido menos denso; } \\
\text { 3) se o material é mais } \\
\text { denso fica mais escuro; }\end{array}$ \\
\hline
\end{tabular}
ISSN 1983-7011 


\begin{tabular}{|c|c|c|c|c|}
\hline & $\begin{array}{l}\text { Depois da aula. } \\
\text { Janaina: "tem que injetar alguma coisa no paciente que altere a densidade de um } \\
\text { dos tecidos para que o contraste fique maior na imagem." } \\
\text { Morgana: "para distinguir um tecido do outro senão vamos ver a mesma cor na } \\
\text { imagem" }\end{array}$ & $\begin{array}{l}\text { escura, em relação a } \\
\text { densidade, dependerá do } \\
\text { tipo de exame que for } \\
\text { feito; } \\
\text { 3) apenas olhar para a } \\
\text { imagem, depois de fazer } \\
\text { o exame, não vai fazer } \\
\text { com que vejamos as } \\
\text { diferenças entre tecidos } \\
\text { com densidades } \\
\text { semelhantes. } \\
\text { Depois da aula. } \\
\text { Não há nenhum } \\
\text { equivoco. }\end{array}$ & $\begin{array}{l}\text { densidade, } \\
\text { imagem. }\end{array}$ & $\begin{array}{l}\text { 4) se o material é menos } \\
\text { denso fica mais claro; } \\
\text { 5) é suficiente olhar a } \\
\text { imagem formada para } \\
\text { distinguir tecidos com } \\
\text { densidades parecidas. } \\
\text { Depois da aula: } \\
\text { 6) se é alterado a } \\
\text { densidade de um dos } \\
\text { tecidos, aumenta-se o } \\
\text { contraste na imagem. }\end{array}$ \\
\hline $\begin{array}{l}\text { Grupo2: } \\
\text { Marcelo e } \\
\text { Marta }\end{array}$ & $\begin{array}{l}\text { Antes da aula. } \\
\text { Marta: "como você estava comentando". } \\
\text { Marcelo: "que são duas densidades diferentes". } \\
\text { Marta: "isto, são parecidas, mas são diferentes, e daí você comentou da } \\
\text { voltagem". } \\
\text { Marcelo: "precisa regular a voltagem para sensibilizar uma menor densidade". } \\
\text { Marta: "mas, se elas têm densidades parecidas às imagens vão ficar muito } \\
\text { parecidas". } \\
\text { Marcelo: "mas vai ficar uma mancha". } \\
\text { Marta: "sim, vai ficar uma mancha, precisa ter uma voltagem mínima para poder } \\
\text { identificar uma das densidades e daí o que for mais denso vai ficar mais claro". } \\
\text { Marcelo: "pois os Raios-X não atravessam". } \\
\text { Marta: "os Raios-X são mais absorvidos. O contraste é justamente isso que vai } \\
\text { aparecer mais claro e do mais escuro, daí se a gente calibra para pegar o mínimo, } \\
\text { daí a outra vai ser mais clara". } \\
\text { Marcelo: "acho que teria que fazer um teste, por exemplo, achar a voltagem } \\
\text { mínima e daí aumentar e diminuir um pouco para ver qual se consegue a melhor } \\
\text { imagem, vai chegar um ponto que atravessa as duas densidades e "estraga" a } \\
\text { imagem", } \\
\text { Marta: "fica uma parte muito clara e daí não dá para diferenciar qual é qual". }\end{array}$ & $\begin{array}{l}\text { Antes da aula: } \\
\text { 1) o que é mais denso vai } \\
\text { ficar mais claro. Isto } \\
\text { depende de qual exame é } \\
\text { feito; } \\
\text { 2) os Raios-X são mais } \\
\text { absorvidos se por onde } \\
\text { passam encontram } \\
\text { materiais mais densos. } \\
\text { Depois da aula. } \\
\text { Não há nenhum } \\
\text { equivoco. }\end{array}$ & $\begin{array}{l}\text { Antes da } \\
\text { aula: } \\
\text { densidade, } \\
\text { voltagem, } \\
\text { imagem, } \\
\text { contraste, } \\
\text { absorção, } \\
\text { amperagem. } \\
\text { Depois da } \\
\text { aula. } \\
\text { densidade, } \\
\text { voltagem, } \\
\text { contraste. }\end{array}$ & $\begin{array}{l}\text { Antes da aula: } \\
\text { 1) regulando a voltagem } \\
\text { sensibiliza uma menor } \\
\text { densidade; } \\
\text { 2) os Raios-X não } \\
\text { atravessam tecidos com } \\
\text { densidade elevada; } \\
\text { 3) se o tecido possui } \\
\text { densidade parecida às } \\
\text { imagens também ficam } \\
\text { parecidas; ter uma } \\
\text { 4) precisa para } \\
\text { voltagem mínima para } \\
\text { poder identificar uma das } \\
\text { densidades; } \\
\text { 5) podemos ir variando a } \\
\text { voltagem para ver qual } \\
\text { imagem formada é mais } \\
\text { nítida; da } \\
\text { 6) dependendo }\end{array}$ \\
\hline
\end{tabular}




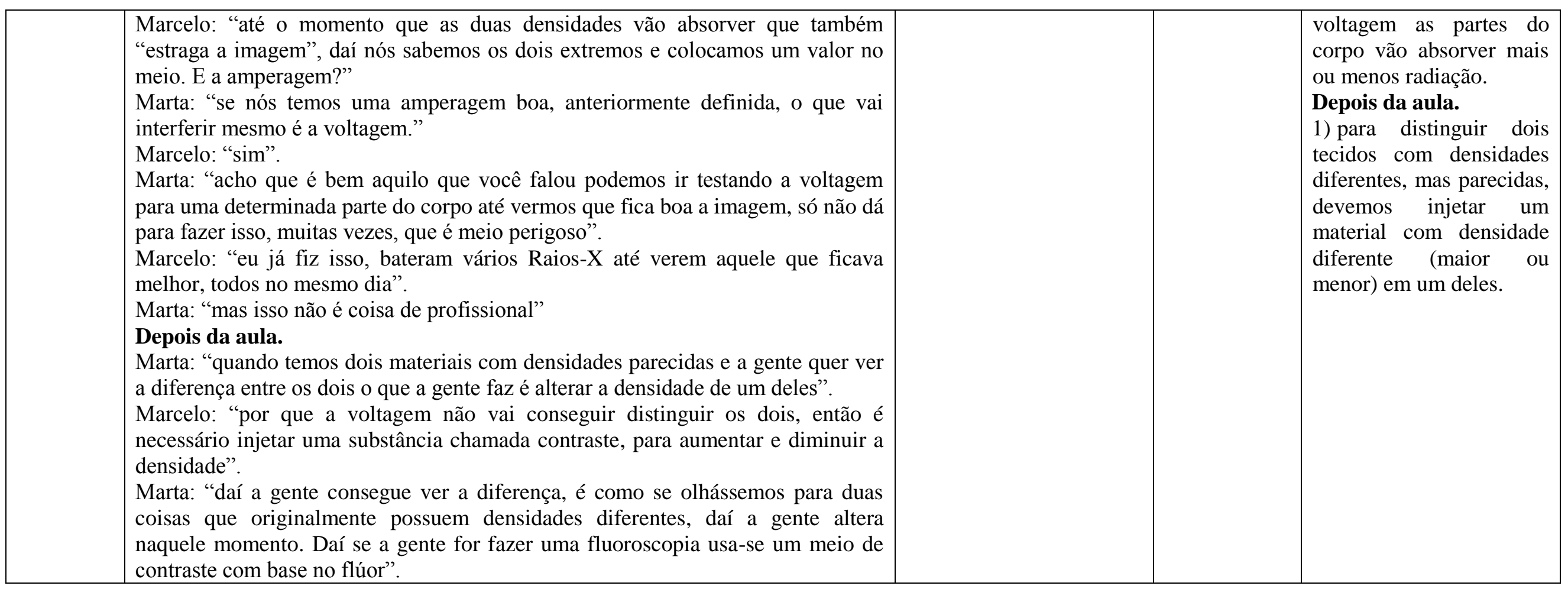

Na Tabela 3 temos a análise da terceira situação-problema que é: "suponham que vocês precisam destruir células cancerígenas de um paciente e estão em um hospital equipado para tanto: a) qual tipo de radiação deve-se utilizar? Por quê? Justifique através de explicações físicas;

b) quais os procedimentos de segurança que teríamos que fazer?"

Tabela 3 - Análise das respostas à terceira situação-problema.

\begin{tabular}{|l|l|l|l|l|}
\hline $\begin{array}{l}\text { Nomes } \\
\text { (fictícios) }\end{array}$ & Transcrição do respondido pelos alunos: terceira situação-problema. & $\begin{array}{l}\text { Equívocos } \\
\text { apresentados }\end{array}$ & $\begin{array}{l}\text { Prováveis } \\
\text { Conceitos-em- }\end{array}$ & $\begin{array}{l}\text { Prováveis teoremas-em- } \\
\text { ação }\end{array}$ \\
\hline
\end{tabular}




\begin{tabular}{|c|c|c|c|c|}
\hline & & & ação & \\
\hline $\begin{array}{l}\text { Grupo1: } \\
\text { Morgana } \\
\text { e } \\
\text { Janaina }\end{array}$ & $\begin{array}{l}\text { Antes da aula. } \\
\text { Morgana: "se você quiser destruir uma célula cancerígena deve utilizar uma } \\
\text { radiação que rompa a membrana desta célula. Como a radiação alfa é muito fraca } \\
\text { a beta é mais utilizada para romper a membrana sem causar muito dano ao } \\
\text { paciente". } \\
\text { Janaina: "gama é muito intensa para isso. Os Raios-X talvez também pudessem } \\
\text { serem adequados, mas eu acredito mais na beta. } \\
\text { Morgana: "e tem que cuidar para não prejudicar muito o paciente, para não } \\
\text { acabar destruindo muitas células boas, acho que estes seriam os procedimentos de } \\
\text { segurança." } \\
\text { Janaina: "também tentar utilizar radiação com intensidade moderada e a } \\
\text { quantidade deve ser adequada para cada tipo de paciente, cada paciente diferente } \\
\text { deve ter uma dosagem diferente". } \\
\text { Morgana: "o tipo de radiação também depende de onde precisa alcançar". } \\
\text { Depois da aula. } \\
\text { Janaína: "se a radiação pode ser injetada diretamente nas células cancerígenas } \\
\text { usa-se radiação alfa e beta, para que elas não se espalhem pelo resto do corpo } \\
\text { atingindo as células normais". } \\
\text { Morgana: "em outros casos em que não se pode aplicar diretamente você usa os } \\
\text { Raios-X ou os Raios Gama". } \\
\text { Janaína: "pois eles têm um capacidade de penetração maior, então eles não vão } \\
\text { ser freados pela pele como aconteceria com as partículas alfa". }\end{array}$ & $\begin{array}{l}\text { Antes da aula: } \\
\text { 1) a radiação alfa } \\
\text { possui energia } \\
\text { suficiente para } \\
\text { romper a membrana } \\
\text { celular, ao contrário } \\
\text { do que os alunos } \\
\text { afirmaram; } \\
\text { 2) como a radiação } \\
\text { gama é intensa, ela } \\
\text { vai romper as } \\
\text { células, ao contrário } \\
\text { do que os alunos } \\
\text { afirmaram. } \\
\text { Depois da aula: } \\
\text { não há equívocos. }\end{array}$ & $\begin{array}{l}\text { Antes da aula: } \\
\text { membrana, } \\
\text { célula, radiação } \\
\text { alfa, beta, gama } \\
\text { e Raios-X. } \\
\text { Depois da } \\
\text { aula: } \\
\text { célula, radiação } \\
\text { alfa, beta, gama } \\
\text { e Raios-X. }\end{array}$ & $\begin{array}{l}\text { Antes da aula: } \\
\text { 1) para destruir uma } \\
\text { célula cancerígena deve- } \\
\text { se utilizar uma radiação } \\
\text { que rompa a membrana } \\
\text { desta célula; } \\
\text { 2) a radiação alfa possui } \\
\text { baixa energia para } \\
\text { romper a membrana } \\
\text { celular; } \\
\text { 3) a radiação gama é } \\
\text { muito intensa para } \\
\text { romper a membrana } \\
\text { celular; } \\
\text { 4) a quantidade } \\
\text { radiação é específica para } \\
\text { cada paciente; } \\
\text { 5) o tipo de radiação } \\
\text { depende de onde se quer } \\
\text { alcançar. } \\
\text { Depois da aula: } \\
\text { 6) utiliza-se radiação alfa } \\
\text { e beta quando se pode } \\
\text { aplicar a radiação direto } \\
\text { nas células cancerígenas; } \\
\text { 7) as radiações alfa e beta } \\
\text { tem alcance menor que } \\
\text { os raios gamas e os } \\
\text { Raios-X; } \\
\text { 8) nos casos onde não se }\end{array}$ \\
\hline
\end{tabular}




\begin{tabular}{|c|c|c|c|c|}
\hline & & & & $\begin{array}{l}\text { pode aplicar radiação, } \\
\text { diretamente, usa-se } \\
\text { Raios-X e raios gama; } \\
\text { 9) os Raios-X e os raios } \\
\text { gama podem penetrar } \\
\text { mais do que a radiação } \\
\text { alfa e beta. }\end{array}$ \\
\hline $\begin{array}{l}\text { Grupo2: } \\
\text { Marcelo } \\
\text { e Marta }\end{array}$ & $\begin{array}{l}\text { Antes da aula. } \\
\text { Marcelo: "seria a radiação gama?" } \\
\text { Marta: "eu acho que sim, pelo menos uma radiação com energia suficiente para } \\
\text { quebrar a membrana da célula e destruir o DNA dessas células cancerígenas que } \\
\text { daí elas morrem". } \\
\text { Marcelo: "os Raios-X rompem as membranas, mas o que é mais perigoso são os } \\
\text { raios gama que atravessa todo o corpo, por que se os Raios-X fossem mais } \\
\text { perigosos que os raios gamas eles seriam mais perigosos do que realmente são. Se } \\
\text { colocarmos na região onde tem o câncer uma substância que absorve mais } \\
\text { radiação, a radiação gama não vai ter mais probabilidade de destruir as células?" } \\
\text { Marta: "sim, tu diz se aumentarmos a densidade daquelas células?" } \\
\text { Marcelo: "a minha esposa fez, mas falou que apenas emitiam radiação nela, não } \\
\text { injetavam nada". } \\
\text { Marta: "é que tem dois tipos: a braquiterapia que é no local e a outra que não } \\
\text { lembro o nome que é externa, só que a que é externa mata também células } \\
\text { saudáveis. Quanto aos procedimentos que temos que fazer, temos que usar } \\
\text { proteção de chumbo para isolar a área de preferência e proteger os materiais, com } \\
\text { densidades grandes, por exemplo, o chumbo. } \\
\text { Marcelo: "o técnico deveria estar atrás de uma parede com vestimenta adequada". } \\
\text { Depois da aula. } \\
\text { Marcelo: "nós temos dois problemas, um quando podemos agir no local e quando } \\
\text { não podemos agir no local". } \\
\text { Marta: "as duas são radioterapias, a que age no local é a braquiterapia e quando } \\
\text { age no todo é a teleterapia. As diferenças: quando a gente age no local como }\end{array}$ & $\begin{array}{l}\text { Antes da aula: } \\
\text { 1) os Raios-X são } \\
\text { menos perigosos do } \\
\text { que os raios gama. } \\
\text { Nem sempre isso é } \\
\text { verdadeiro, pois os } \\
\text { Raios-X possuem } \\
\text { um espectro mais } \\
\text { amplo do que os } \\
\text { raios gama, } \\
\text { podendo ser menos } \\
\text { energéticos, com } \\
\text { igual energia ou } \\
\text { mais energético, ao } \\
\text { contrário do que os } \\
\text { alunos afirmaram; } \\
\text { 2) se colocarmos, } \\
\text { na região onde tem } \\
\text { o câncer, uma } \\
\text { substância que } \\
\text { absorve mais } \\
\text { radiação, a radiação } \\
\text { gama vai ter mais } \\
\text { probabilidade de }\end{array}$ & $\begin{array}{l}\text { Antes da aula: } \\
\text { Raios-X, célula, } \\
\text { raios gama, } \\
\text { densidade, } \\
\text { chumbo. } \\
\text { Depois da } \\
\text { aula: } \\
\text { radiação alfa e } \\
\text { beta, prótons, } \\
\text { nêutrons, } \\
\text { massa, chumbo, } \\
\text { transmissão, } \\
\text { tempo, } \\
\text { tamanho, ossos, } \\
\text { músculos, } \\
\text { órgãos, energia, } \\
\text { Raios-X e raios } \\
\text { gama, } \\
\text { aceleradores } \\
\text { linear e circular, } \\
\text { solenoide, } \\
\text { percurso, } \\
\text { elétron, } \\
\text { aceleração. }\end{array}$ & $\begin{array}{l}\text { Antes da aula: } \\
\text { 1) a radiação gama } \\
\text { possui energia suficiente } \\
\text { para romper a membrana } \\
\text { celular; } \\
\text { 2) a radiação gama } \\
\text { possui mais energia do } \\
\text { que os Raios-X; } \\
\text { 3) se for colocada uma } \\
\text { substância mais densa } \\
\text { próximo a células } \\
\text { cancerígenas, estas são } \\
\text { mais facilmente } \\
\text { destruídas; proter da } \\
\text { 4) para se proteger } \\
\text { radiação é necessário } \\
\text { usar proteção de chumbo. } \\
\text { Depois da aula: } \\
\text { 1) quando usa-se } \\
\text { radiação apenas no local } \\
\text { chamamos de } \\
\text { braquiterapia; } \\
\text { 2) quando a fonte de } \\
\text { radiação é externa, }\end{array}$ \\
\hline
\end{tabular}


precisa atingir curtos alcances a gente usa radiações que possuem massa e são facilmente paradas, que seriam a radiação alfa e a radiação beta".

Marcelo: "Isso, beta: positivo e negativo e alfa: dois prótons e dois nêutrons

Coloca-se em cápsulas bem pequenas de $4,5 \mathrm{~mm}$ ".

Marta: "estas cápsulas são revestidas de chumbo."

Marcelo: "quando chegam ao local é tirado esta cápsula de chumbo".

Marta: "para poder transmitir".

Marcelo: "quanto é o tempo necessário?"

Marta: "você falou, acho que é uns dez minutos".

Marcelo: "quando eu fiz era externo e não interno, mas era quinze minutos e intervalo de 3 minutos, mas não era grave era no começo, então pessoas que possuem câncer mais grave deve ser mais tempo.

Marta: "também depende do tamanho do câncer. Como a teleterapia é externa e a radiação terá que atravessar ossos, músculos”.

Marcelo: "órgãos internos".

Marta: "até chegar ao tumor mesmo, precisa então possuir mais energia, que é a radiação gama ou outras frequências dos Raios-X.

Marcelo: "dentro do espectro dos Raios-X só que com mais energias, mais próximo dos raios gama. Para conseguir os Raios-X com altas energias temos os aceleradores lineares e circulares".

Marta: "o circular tem mais vantagem, por que dá para colocar mais solenoides, então você vai aumentar mais a voltagem".

Marcelo: "então o elétron é mais acelerado, pois percorre um percurso maior e quando colidir com a fonte, que são outros equipamentos que existem, vão produzir Raios-X com mais energia".

Marta: "isto. Quanto as proteções, é o que nós falamos antes, utilizar chumbo, tanto que as cápsulas usadas na braquiterapia são revestidas por chumbo." destruir as células,

ao contrário do que

os

alunos

afirmaram.

Depois da aula:

1) as cápsulas

usadas

na

braquiterapia são

levadas até as

células

cancerígenas por

um tubo revestido

de chumbo e não é

tirada a capa dentro

do corpo da pessoa,

ao contrário do que

os

alunos

afirmaram;

2) a radiação, na teleterapia, precisa

possuir mais

energia que na

braquiterapia, ao

contrário do que os

alunos afirmaram. chamamos de teleterapia;

3) a teleterapia e a

braquiterapia formam a

radioterapia;

4) na braquiterapia utilizam-se radiações que possuem curto alcance (alfa e beta);

5) a radiação alfa é composta por dois prótons e dois nêutrons;

6) a radiação beta pode ser positiva e negativa;

7) pessoas que possuem câncer mais grave precisam ficar expostas mais tempo à radiação;

8) a radiação, na teleterapia, precisa possuir mais energia do que na braquiterapia;

9) quanto mais solenóides compõem o gerador maior será a voltagem

consequentemente energia dos Raios-X;

10) para se proteger das radiações ionizantes, deve-se utilizar chumbo. 
$\mathrm{Na}$ terceira situação-problema os alunos tiveram argumentos para responder antes e depois do teste.

Os alunos do grupo 1 não apresentaram nenhum equivoco depois da aula, ao contrário do pré-teste, em que apresentaram dois. Entretanto, eles não explicaram por que as radiações alfa e beta possuem pouca capacidade de penetração, ao contrário da radiação gama e dos Raios-X. Esta resposta enfatiza a descrição em detrimento da explicação e a descrição não é uma característica de aprendizagem significativa. Não sabemos se eles sabem explicar (o que observamos na entrevista semiestruturada).

Os alunos do grupo 2 apresentaram dois equívocos diferentes antes e após a aula. Eles explicaram como ocorre a radioterapia, apresentando as semelhanças e diferenças entre os dois tipos, quando e porque são utilizadas determinadas radiações em detrimento de outras e as características delas. Justificaram por que em alguns casos usariam uma radiação e não outra e como é feito o emprego destas. A resposta deste grupo foi bastante explicativa, com exemplos relacionados ao dia-a-dia, o que nos fornecem indícios de aprendizagem significativa, exceto nos equívocos apresentados.

\section{Considerações finais}

Através da análise dos discursos dos alunos, que eles utilizaram para buscarem resolver as situações-problema propostas, podemos perceber que, inicialmente, eles pouco sabiam sobre os assuntos trabalhados no curso. A partir da aplicação, a maioria deles apresentou indícios de que acrescentaram conhecimentos na estrutura cognitiva, no sentido que aumentaram os conceitos usados e as ligações entre eles.

No final do curso, depois de contínuas retomadas dos assuntos, foi aplicado um pós-teste, de modo a identificar se as intervenções feitas tiveram resultados positivos, no sentido de facilitar uma aprendizagem significativa. Os resultados foram positivos, conforme pode-se conferir em PARISOTO (2011).

Uma importante contribuição do trabalho é que ele divulga uma forma dos professores de Física ensinarem conceitos de Física Médica de modo integrado, apresentando situações-problema para tanto. Além disso, foram identificados invariantes operatórios nessa área, que é pouco explorada, que pode vir a facilitar futuras pesquisas neste campo de atuação e favorecer um ensino que considere os conhecimentos-em-ação e os teoremas-em-ação por nós identificados. 
Finalmente, cabe reiterar que este trabalho, relata apenas uma parte de uma das implementações da proposta, foram feitas quatro, este refere-se à última.

\section{Referências}

ANDRÉ, Marli Eliza Dalmazo Afonso de. Etnografia da prática escolar. São Paulo: Papirus Editora, 1998.

ANDRÉ, Marli Eliza Dalmazo Afonso de. Estudo de caso em pesquisa e avaliação educacional. Brasília/DF: Liber Livro Editora Ltda, 2005.

AUSUBEL, David Paul. Retenção e aquisição de conhecimento: uma perspectiva cognitiva. Dordrecht: Kluwer Academic Publishers, 2002.

DORNELES, Pedro Fernando Teixeira; ARAÚJO, Ives Solano; VEIT, Eliane Angela. A integração entre atividades computacionais e experimentais: um estudo exploratório no ensino de circuitos CC e CA em Física Geral. VI Encontro Nacional de Pesquisadores em Educação em Ciências. Anais, Florianópolis, 2007.

MOREIRA, Marco Antonio MOREIRA. Mapas conceituais como instrumentos para promover a diferenciação conceitual progressiva e a reconciliação integrativa. Ciência e Cultura, São Paulo, v. 32, n. 4, p. 474-479, novembro 1980.

MOREIRA, Marco Antonio. Mapas conceituais e aprendizagem significativa. São Paulo: Centauro Editora, 2010.

NOVAK, Joseph; GOWIN, Bob. Aprender a Aprender. Lisboa: Cambridge University Press, 1984.

PARISOTO, Mara Fernanda. O ensino de conceitos do eletromagnetismo, óptica, ondas e Física moderna e contemporânea através de situações na Medicina. Dissertação de Mestrado, Universidade Federal do Rio Grande do Sul, Porto Alegre, Rio Grande do Sul, Brasil, 2011.

PRAIN, Vaughan; WALDRIP, Bruce. An exploratory study of teachers' and students' use of multi-modal representations of concepts in primary science. International Journal of Science Education, v. 28, n. 15, p. 1843-1866, October 2006.

VERGNAUD, Gerard. Teoria dos campos conceituais. Anais do $1^{\mathbf{0}}$ Seminário Internacional de Educação Matemática do Rio de Janeiro, outubro 1993. 